El nacimiento de la rata Kaguya por partenogénesis (sin fecundación) presentó particularidades muy interesantes que se reflejaron en los titulares: "Revolución genética: japoneses generaron ratón sin padre" (El Mercurio) o "¿Serán prescindibles los hombres?" (La Nación). Nada se dijo acerca de que los investigadores construyeron 598 oocitos no viables antes de que finalmente sobrevivieran dos, de uno de los cuales nació Kaguya. En ninguno de los periódicos analizados se mencionó la necesidad de la contribución paterna para mantener el linaje -más bien sus versiones se centraron en todo lo contrario-, a pesar de que los autores resaltaron explícitamente este hecho en la última frase de las conclusiones, espacio reservado para exponer los juicios principales.

Además, se identificaron errores e incoherencias, particularmente en los datos numéricos, que reflejan descuido y premura al redactar los artículos periodísticos. En algunos casos era evidente que las distorsiones se debían al descuido o al ajuste de la información a la corriente ideológica del autor.

La iniciativa de las revistas científicas de enviar comunicados de prensa a los medios tiene una buena aceptación por parte de los periodistas y puede tener un notable impacto en la cobertura de la información científica. Sin embargo, el proceso de adaptación de la información científica al lenguaje periodístico implica transformar el léxico, el estilo y la forma de argumentar o explicar los resultados. Lamentablemente, con frecuencia esto va acompañado de la adición o la supresión de información, alteraciones de los datos, cambios en la jerarquía y el énfasis correcto de la información, malinterpretaciones del impacto social esperado, etc.

Está comprobado que al llevar la información científica a los medios masivos de comunicación ocurren distorsiones. Es necesario prestar especial atención al rigor con que se lleva a la población la información científica relacionada con la salud pública. (Veneu F, Amorim LH, Massarani L. Science journalism in Latin America: how the scientific information from a scientific source is accommodated when it is transformed into a journalistic story. J Scie Comm. 2008;(1). Hallado en http://jcom.sissa. it/archive/07/01/Jcom0701\%282008\%29A03/. Acceso el 6 de mayo de 2008.)

FE DE ERRATA

\title{
Trypanosoma cruzi I: único tipo del parásito tripanosómico circulante en Panamá (Rev Panam Salud Publica/Pan Am J Public Health 2008;23(5):357)
}

La redacción llama la atención de los lectores sobre la siguiente errata aparecida en la versión publicada de este artículo de la sección de Instantáneas:

P. 357. Versión equivocada: "Diversos autores han atribuido esta heterogeneidad a la variabilidad genética del trematodo Trypanosoma cruzi". Versión correcta: "Diversos autores han atribuido esta heterogeneidad a la variabilidad genética del protozoario Trypanosoma cruzi". 